\title{
Propane Sultone Mutagenesis in Relation to Treatment Conditions
}

\author{
C. Singh and A. P. Shamsherry ${ }^{1}$ \\ Regional Research Laboratory, Canal Road, \\ Jammu Tawi-180001, India
}

Accepted April 10, 1984

Rapid and fruitful strides have been made in artificial induction of mutations through sound developments in treatment methodology. These developments have led not only to identification and evaluation of several physical factors which modulate chemical mutagenesis but also facilitate better understanding and hence exploitation of the mutation process.

It is now established that the magnitudes of both physiological as well as genetic effects of chemical mutagens are greatly dependent upon various physcial conditions of treatment prevailing prior to, during and following treatment (Kamra and Brunner 1970, Konzak et al. 1972, Singh and Kaul 1978b, Singh et al. 1980, Hasegawa and Inoue 1980, Prina and Favret 1983).

The present study records mutagenic activity of 1, 3-Propane sultone (PS), in relation to certain treatment conditions. Earlier studies have shown PS to be a potent carcinogen (Druckrey et al. 1968 and 1970, Ulland et al. 1971) with equally well documented radiomimetic and mutagenic attributes (Kaul and Singh 1971, Singh and Kaul 1973, Zutshi and Kaul 1975, Osterman Golkar and Wachtmeister 1976, Singh and Kaul 1978b and Singh 1979).

\section{Material and methods}

Genetically pure and uniform sized seeds of barley (Hordeum vulgare var. joti) with $10.8 \%$ original seed moisture content and above $80 \%$ seed germinability were used as test material. Stock solution of PS was always freshly made in distilled water and later diluted to adjust to final concentrations for administering treatments which lasted for 4 hours at $25^{\circ} \mathrm{C}$. To study the effect of temperature treatments were administered in electric ovens maintained at different temperatures $\left(19-30^{\circ} \mathrm{C}\right)$. For evaluation of $\mathrm{pH}$ response mutagenic solutions of PS were made with appropriate buffer systems and adjusted to different levels of $\mathrm{pH}(2.6,3.2,4.6,7.2,8.2)$.

At the termination of the treatment, the seeds were given a quick wash under running tap water and sown in field in rows and each in treatment 300 seeds in 3 replications of 100 seeds each were planted and grown under natural day light conditions. Data on seed lethality and seedling growth was recorded on similarly treated batches of seeds grown over moist filter paper in petridishes. Spike sterility was recorded on $25 \mathrm{M}_{1}$ spikes picked up randomly from each treatment. Spikes of $M_{1}$ plants harvested at maturity were sown in nursery to raise $M_{2}$ seedlings for

${ }^{1}$ Department of Botany, Hindu College, Moradabad U. P., India. 
mutation analysis. The chlorophyll deficient mutations were analysed and classified according to the method of Gustaffson (1940), and mutagenic effectiveness and efficiency was computed by the method of Konzak et al. (1964).

Msd = Mutation frequency on $\mathrm{M}_{2}$ seedling basis

$\mathrm{Cxt}=$ Concentration of mutagen $\times$ duration of treatment in hours

$\mathrm{L}=$ Seed lethality $(\%), \mathrm{I}=$ Seedling injury $(\%), \mathrm{S}=$ Spike sterility $(\%)$.

\section{Results and discussion}

Concentration of mutagen, its hydrogen ion concentration and treatment temperature caused an appreciable effect on physiological as well as genetic effects
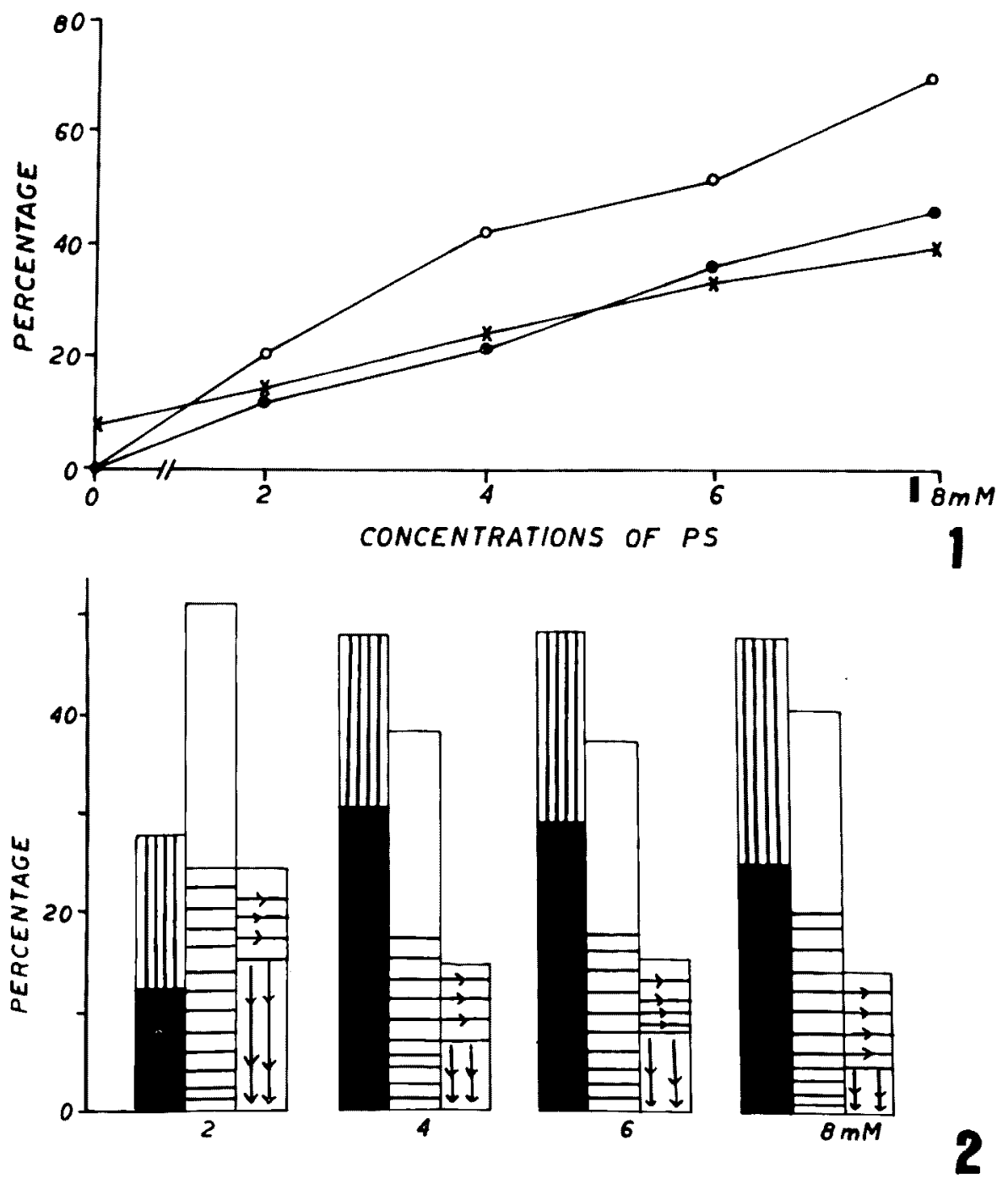

Figs. 1-2. 1, effect of concentration on PS induced seed lethality $(\bullet)$, seedling growth injury $(O)$, and spike sterility $(x)$ in barley. 2, PS induced spectrum of chlorophyll mutations in barley Albina (solid black column), Xantha (vertical stripes), Viridis (horizontal stripes), Alboviridis (open column), Alboxantha (vertical arrows) and Misc. (horizontal arrows). 
of PS. Treatments with 2, 4, 6 and $8 \mathrm{mM}$ of PS caused significant amount of seed lethality, seedling growth injury and spike sterility (Fig. 1). With an increase in concentration of PS from 2 to $8 \mathrm{mM}$ seed lethality, seedling growth injury and spike sterility, showed a more than three fold increase. Whereas with the same rise in concentration of mutagen mutation frequency recorded a 3.5 fold rise. Highest mutation frequency $(6.95 \%)$ was observed in $8 \mathrm{mM}$ treatment followed by $6 \mathrm{mM}$, $4 \mathrm{mM}$ and $2 \mathrm{mM}$ in that order. Higher mutagenic effectiveness and efficiency was, however, recorded in case of $6 \mathrm{mM}$ treatment (Table 1).

Table 1. Effect of different concentrations of PS on mutation frequency, mutagenic effectiveness and mutagenic efficiency

\begin{tabular}{|c|c|c|c|c|c|c|c|c|}
\hline \multirow[b]{2}{*}{ Concentration } & \multirow{2}{*}{$\begin{array}{c}\mathbf{M}_{1} \\
\text { spikes } \\
\text { analysed }\end{array}$} & \multirow{2}{*}{$\begin{array}{l}\mathrm{M}_{2} \\
\text { seedlings } \\
\text { tested }\end{array}$} & \multirow{2}{*}{$\begin{array}{l}\text { Mutations/ } \\
100 \mathrm{M}_{1} \\
\text { spikes }\end{array}$} & \multirow{2}{*}{$\begin{array}{c}\text { Mutations/ } \\
100 \mathrm{M}_{2} \\
\text { seedlings }\end{array}$} & \multirow{2}{*}{$\begin{array}{c}\text { Mutagenic } \\
\text { effectiveness } \\
\text { Msd/cxt }\end{array}$} & \multicolumn{3}{|c|}{ Mutagenic efficiency } \\
\hline & & & & & & $\underset{\mathrm{L}}{\mathrm{Msd} /}$ & $\begin{array}{c}\text { Msd/ } \\
\text { I }\end{array}$ & $\underset{\mathrm{S}}{\mathrm{Msd} /}$ \\
\hline & 8 & & & 0.0 & 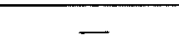 & - & - & - \\
\hline 2.0 & 230 & & & & & 1.150 & 0.093 & 0.041 \\
\hline 4.0 & 276 & 6436 & $22.4 \pm 2.6$ & $3.84 \pm 0.46$ & 0.240 & 0.178 & 0.078 & 0.149 \\
\hline 6.0 & 254 & 5630 & $24.3 \pm 2.4$ & $6.34 \pm 0.94$ & 0.264 & 0.182 & 0.019 & 0.195 \\
\hline 8.0 & 260 & 5483 & $26.0 \pm 3.2$ & $6.95 \pm 0.82$ & 0.217 & 0.152 & 0.010 & 0.167 \\
\hline
\end{tabular}

\pm standard deviation.

Concentrations of 'PS also effected the frequency of diffecent types of chlorophyll deficient mutations (Fig. 2). It is seen from the Fig. 2 that increasing concentrations favoured the appearance of Albina and Xantha type of mutations whereas Alboviridis and Alboxantha mutations were significantly reduced.

Relationship between sterility and frequency of different types of mutations presented in figure show that sterility determined the magnitude of genetic effect but the spectrum of mutations however remained unaltered. The highest mutation frequency $(5.29 \%)$ was recorded at $16-30 \%$ sterility level whereas $\mathbf{M}_{1}$ spikes with highest sterility $(46-60 \%)$ recorded a minimum of mutations. Sterility also effected frequency of different types of chlorophyll deficient mutations (Fig. 3). Increase in sterility caused an adverse effect on the appearance of Albina mutations but not Alboviridis mutations which on the contrary recorded an increase.

\section{Effect of treatment temperature}

Treatment temperature caused a profound effect on PS induced growth injury Fig. 4). Growth damage measured in terms of seed lethality, seedling growth njury, spike sterility and mutagenic frequency recorded a linear increase with rises n treatment temperature. With a rise of temperature from $10^{\circ} \mathrm{C}$ to $30^{\circ} \mathrm{C}$ a 3 to 4 fold increase in seed lethality, seedling growth injury and spike sterility was noted. However significant amounts of seed lethality and seedling growth injury were caused in treatments administered at $20^{\circ} \mathrm{C}$ and above. The frequency of $\mathrm{M}_{1}$ spikes and $\mathrm{M}_{2}$ seedlings segregating for mutations showed 4 and 12 fold increase respectively (Table 2). Mutagenic effectiveness and mutagenic efficiency also showed a linear rise with increasing temperature. Higher effectiveness was recorded in the treatments administered at $30^{\circ} \mathrm{C}$ and $25^{\circ} \mathrm{C}$ in that orde. Whereas a maximum of ef- 

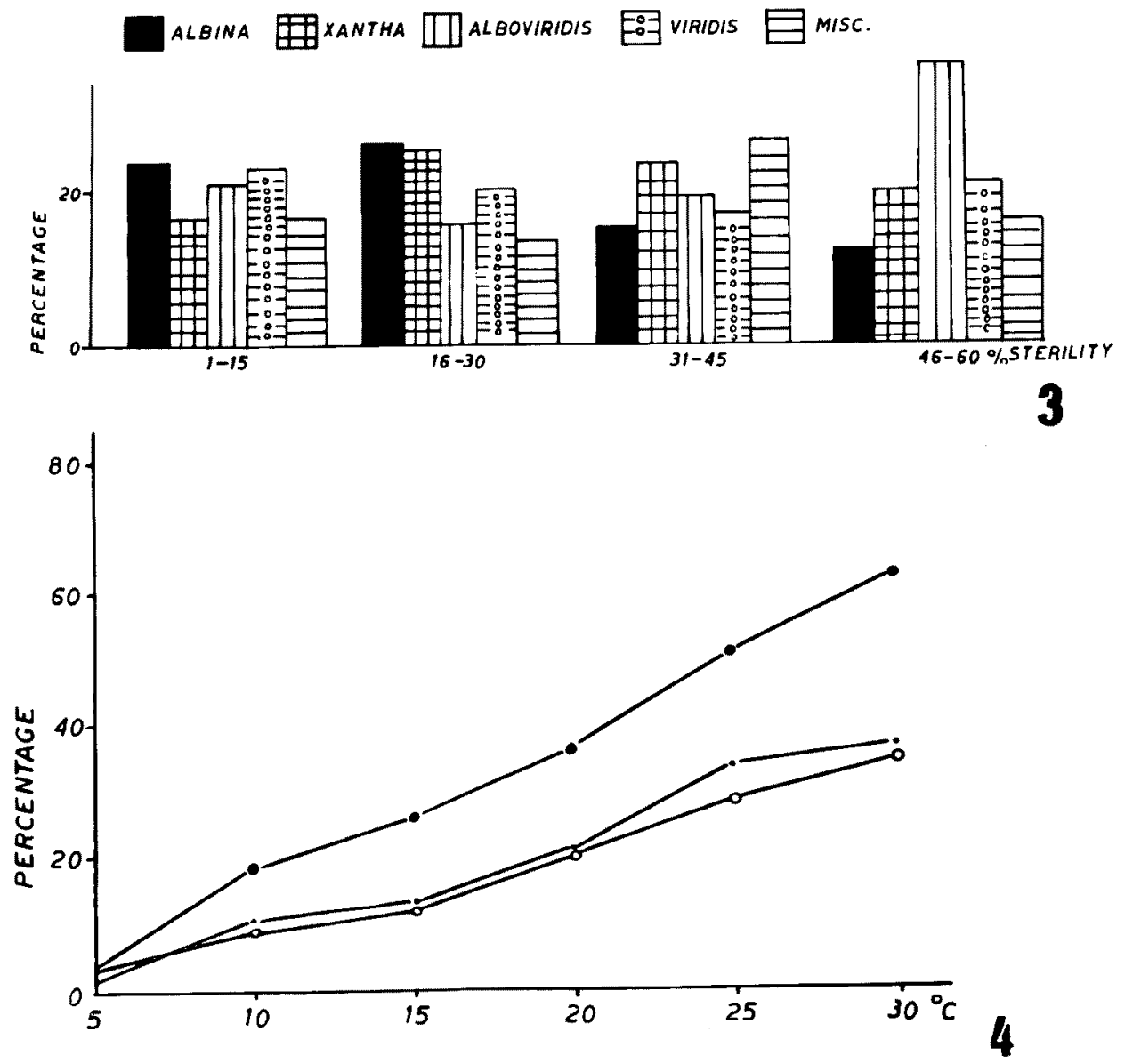

Figs. 3-4. 3, relationship between sterility and spectrum of PS induced mutations in barley. 4, effect of temperature on PS induced seed lethality $(\cdot)$, seedling growth injury $(\bullet)$ and spike sterility $(0)$ in barley.

Table 2. Effect of treatment temperature on PS mutagenesis in barley

\begin{tabular}{|c|c|c|c|c|c|c|c|c|}
\hline \multirow{2}{*}{$\begin{array}{l}\text { Treatment } \\
\text { temperature } \\
{ }^{\circ} \mathrm{C}\end{array}$} & \multirow{2}{*}{$\begin{array}{c}\mathbf{M}_{1} \\
\text { spikes } \\
\text { analysed }\end{array}$} & \multirow{2}{*}{$\begin{array}{l}\text { Mutations/ } \\
100 \mathrm{M}_{1} \\
\text { spikes }\end{array}$} & \multirow{2}{*}{$\begin{array}{c}\mathrm{M}_{2} \\
\text { seedling } \\
\text { analysed }\end{array}$} & \multirow{2}{*}{$\begin{array}{c}\text { Mutations/ } \\
100 \mathrm{M}_{2} \\
\text { seedlings }\end{array}$} & \multirow{2}{*}{$\begin{array}{l}\text { Mutagenic } \\
\text { effectiveness } \\
\text { Msd/cxt }\end{array}$} & \multicolumn{3}{|c|}{ Mutagenic efficiency } \\
\hline & & & & & & $\underset{L}{\operatorname{Msd} /}$ & $\underset{\text { I }}{\mathrm{Msd} /}$ & $\underset{\mathrm{S}}{\mathrm{Msd} /}$ \\
\hline 10 & 2 & & & 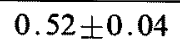 & & 0.055 & 0.03 & 0.055 \\
\hline 15 & 267 & $8.4 \pm 1.3$ & 6754 & $1.0 \pm 0$ & & 56 & 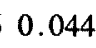 & 0.076 \\
\hline 20 & 254 & $12.3 \pm$ & 61 & $3.2 \pm 0$ & 0. & 0.150 & 0.078 & 0.157 \\
\hline 25 & 230 & $23.0 \pm 1.9$ & 6386 & $5.7 \pm 0.76$ & 0.286 & 0.161 & 0.118 & 0.203 \\
\hline 30 & 236 & $25.9 \pm 1.4$ & 5873 & $6.33 \pm 0.48$ & 0.316 & 0.154 & 0.105 & 0.182 \\
\hline
\end{tabular}

\pm standard deviation.

ficiency was observed at $25^{\circ} \mathrm{C}$ and further rise in temperature adversely effected it. Treatments carried out at lower temperatures i.e. $10-20^{\circ} \mathrm{C}$ were significantly less efficient (Table 2). 


\section{Effect of $\mathrm{pH}$}

The effect of $\mathrm{pH}$ on biological response of PS as measured by seedling growth, root growth injury, spike sterility and chlorophyll mutation frequency showed increase under extreme acidic conditions of $\mathrm{pH}$ (Fig. 5). Significant increase in seedling growth injury, root growth injury and spike sterility was observed at $\mathrm{pH}=$ 2.6 and $\mathrm{pH}=3.2$ Root growth appeared to be more sensitive to low $\mathrm{pH}$ based PS treatments. The frequency of $\mathrm{M}_{2}$ spikes segregating for mutations showed a comparable trend, however, a slightly higher mutation frequency was recorded at $\mathrm{pH}$ 4.6. (Table 3). Higher mutagenic effectiveness was observed at $\mathrm{pH} 4.6$ followed by $\mathrm{pH}=8.7$ and $\mathrm{pH}=3.2$ in that order. Whereas higher efficiency was recorded at pHs $4.6,7.2$, and 3.2 .

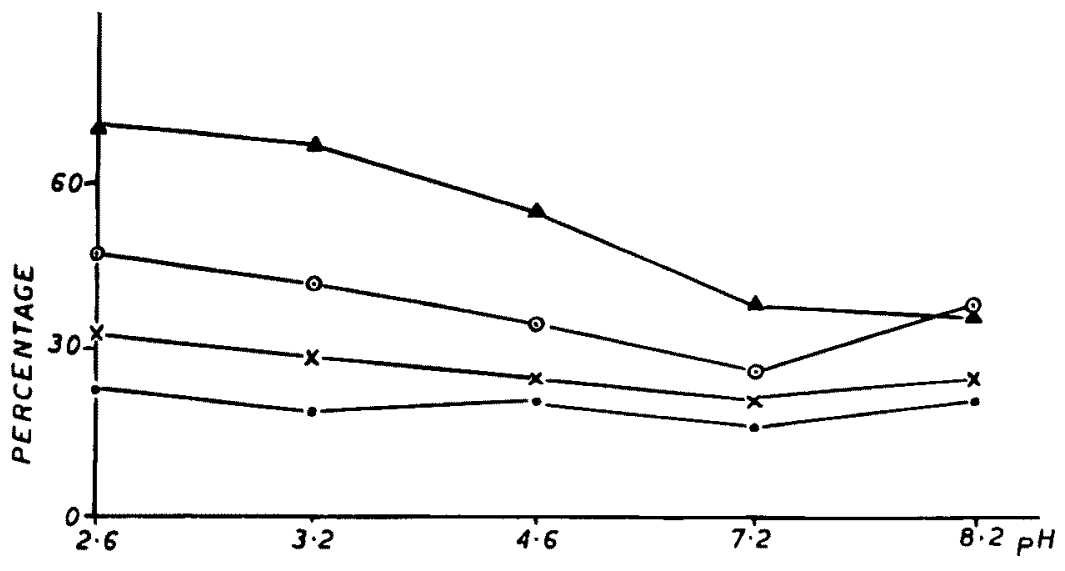

Fig. 5. Effect of pH on PS induced seed lethality $(\bullet)$, seedling growth injury $(\odot)$, root growth injury $(\boldsymbol{\Lambda})$ and spike sterility in barley $(x)$.

Table 3. Effect of pH on PS mutagenesis in barley

\begin{tabular}{|c|c|c|c|c|c|c|c|c|}
\hline \multirow[b]{2}{*}{$\mathrm{pH}$} & \multirow{2}{*}{$\begin{array}{c}\mathrm{M}_{1} \\
\text { spikes } \\
\text { analysed }\end{array}$} & \multirow{2}{*}{$\begin{array}{c}\text { Mutations/ } \\
100 \mathrm{M}_{1} \\
\text { spikes }\end{array}$} & \multirow{2}{*}{$\begin{array}{c}\mathbf{M}_{2} \\
\text { seedlings } \\
\text { analysed }\end{array}$} & \multirow{2}{*}{$\begin{array}{c}\text { Mutations/ } \\
100 \mathrm{M}_{2} \\
\text { seedlings }\end{array}$} & \multirow{2}{*}{$\begin{array}{c}\text { Mutagenic } \\
\text { effectiveness } \\
\text { Msd/cxt }\end{array}$} & \multicolumn{3}{|c|}{ Mutagenic efficiency } \\
\hline & & & & & & $\underset{\mathbf{L}}{\mathrm{Msd} /}$ & $\begin{array}{l}\text { Msd/ } \\
\text { I }\end{array}$ & $\begin{array}{c}\mathrm{Msd} / \\
\mathrm{S}\end{array}$ \\
\hline $\begin{array}{l}\text { Unbuffered } \\
\text { (control) }\end{array}$ & 260 & $18.6 \pm 3.5$ & 6672 & $2.6 \pm 0.22$ & 0.221 & 0.143 & 0.098 & 0.130 \\
\hline 2.6 & 251 & $20.4 \pm 3.8$ & 6336 & $2.9 \pm 0.21$ & 0.244 & 0.123 & 0.061 & 0.089 \\
\hline 3.2 & 292 & $20.8 \pm 4.6$ & 6384 & $3.1 \pm 0.52$ & 0.264 & 0.170 & 0.076 & 0.112 \\
\hline 4.6 & 265 & $22.4 \pm 2.6$ & 6896 & $3.7 \pm 0.45$ & 0.309 & 0.173 & 0.104 & 0.147 \\
\hline 7.2 & 231 & $20.0 \pm 3.5$ & 6176 & $2.5 \pm 0.47$ & 0.210 & 0.158 & 0.096 & 0.118 \\
\hline 8.2 & 228 & $18.6 \pm 2.7$ & 5420 & $3.2 \pm 0.34$ & 0.270 & 0.151 & 0.085 & 0.126 \\
\hline
\end{tabular}

\pm standard deviation

Biological activity of chemical mutagens depends upon their nature, chemical properties and also on the characters of the specific tissue treated. Interacting with these a number of other physical factors of biological, environmental or chemical nature exert their influence to determine magnitudes of physiological as well as genetic effects (Singh and Kaul 1978a, Konzak et al. 1972).

In the present study a significant influence of concentration of mutagen, its $\mathrm{pH}$ 
and treatment temperature was noted. Both the physiological as well as genetic effects of PS recorded a linear rise corresponding with concentration increases (Fig. 1 and Table 1). PS caused significant amount of seed and seedling lethality and LD50 of PS would be around 6-8 $\mathrm{mM} 4 \mathrm{hrs} 25^{\circ} \mathrm{C}$. The spectrum of PS induced mutations comprised of Albina, Xantha, Alboviridis, Alboxantha and Viridis type of mutations. Maculata and Tigrina mutations also appeared but rarely. The frequency of different type of mutations showed a dose dependent effect. Similar dose dependent increases in biological activity of chemical mutagens have been recorded in several studies (Ehrenberg and Gichner 1967, Gichner and Veleminsky 1973, Bhan 1974, Mehra and Man 1974, Sarma et al. 1979, Prina and Favret 1983).

PS caused significant amount of spike sterility which effected the frequency of induced mutations. Higher frequency of mutations (5.29\%) was recorded at 16$30 \%$ sterility and increased sterility reduced yield of mutations. Similar observations have been recorded by Muller (1966), Gichner and Veleminsky (1973) who observed that enhancement in genetic effects was limited by the sterility of $\mathbf{M}_{1}$ plants. Muller and Gichner (1963) and Gichner and Veleminsky (1967) on the contrary recorded increased mutagenicity of nitro compounds together with increased sterility but not seed lethality which remained uneffected. This type of dose response relationship is typical of nitrosamides.

Treatment temperature and $\mathrm{pH}$ of the mutagenic test solution also caused a profound effect on physiological as well as genetic effects of PS. Biological activity of the mutagen increased with rising temperature and higher mutagenic effectiveness and efficiency was recorded in treatments administered at $25^{\circ} \mathrm{C}$ and $30^{\circ} \mathrm{C}$. Such a enhancing influence of temperature on bilogical effects of different classes of chemical mutagens has been recorded in several studies (Konzak et al. 1961, Blixt 1967, Kapoor 1967, Kaul and Zutshi 1972, Singh and Kaul 1973 and 1978a). Temperature determines rate of hydrolysis and uptake of the mutagen across the cell membrane (Konzak et al. 1964, Ehrenberg et al. 1966 and Konzak et al. 1972). In this study exact mechanism underlying the influence of temperature on PS induced damage is not clear. However, it may be pointed out that the final effect observed may be dependent on many factors, such as hydrolysis, extent of alkylation, and permeability of the mutagen across the cell membrane. All these factors may be influenced by temperature reflecting the ultimate biological response produced. The biological responses of PS influenced by hydrogen ion concentration of the treatment solution are fairly well pronounced under extreme acidic and slight alkaline conditions of $\mathrm{pH}$. From the results it is clear that the low $\mathrm{pH}$ is associated with effects leading to lethality than is the alkaline $\mathrm{pH}$ as observed in case of seedling growth injury, root growth injury, spike sterility and mutation frequency.

Increased activity of low $\mathrm{pH}$ based treatments with chemical mutagens has earlier been recorded with alkyl sulphonates and alkylalkane sulphonates (Ramanna and Natarajan 1965, Narayanan 1970, Konzak et al. 1972, Mohan Rao 1972, Augustine et al. 1975) and nitroso-compounds (Veleminsky and Gichner 1970, Kalia and Singh 1973).

In the present study a mild increase in activity of PS was observed in low $\mathrm{pH}$ based treatments. One possibility is that $\mathrm{pH}$ may influence the effective concen- 
tration of PS i.e. the amount of PS actually available for reaction with nucleophilic target sites in biological organisms as opposed to the actual and initial concentration used thereby resulting in a differential response of biological activity. A critical comparison of $\mathrm{pH}$ changes at the termination of treatments showed a rise in $\mathrm{pH}$ of low $\mathrm{pH}$ based treatments thus indicating hydrolysis of the mutagen. The increased growth injury at low $\mathrm{pH}$ may be attributed to injurious hydrolytic products. Relevance of $\mathrm{pH}$ in PS mutagenesis, however, need to be evaluated in greater detail for its efficient usage.

\section{Summary}

Effects of concentration, treatment temperature and hydrogen ion concentration on biological activity of 1,3-Propane sultone (PS) were studied in barley (Hordeum vulgare). Physiological as well as genetic effects of mutagen showed a linear increase with increase in the concentration of mutagen and its treatment temperature. Higher mutagenic effectiveness and efficiency of PS was recorded following treatment with $6 \mathrm{mM}$ and at $25^{\circ} \mathrm{C}$. The effect of $\mathrm{pH}$ was apparent on root growth injury, as compared to seedling growth damage. A higher mutagenic efficiency was however, recorded at $\mathrm{pH}=4.6$.

\section{References}

Augstine, V. J., Palanichamy, K. and Siddiq, E. A. 1975: Influence of pH on mutagenic specificity and efficiency of hydroxylamine, hydrazide and methyl methana sulfonate in two rice types. Radiat. Bot. 15: 267-277.

Bhan, A. K. 1974. Induced mutations in rices growth in Haryana. Ph. D. Thesis Kurukshetra University, 240.

Blixt, S. 1967. Studies on induced mutations in peas XXI. Effect of hydrogen ion concentration on seed treatment with EMS. Agri. Hort. Genet. 25: 112-120.

Druckery, H., Krause, H. and Preussmann, R. 1968. Propane sultone a powerful carcinogen. Natur. Wissenschaften 55: 449.

_, _, - Ivankovic, S., Landschaften, C and Jimmy, L. 1970. Carcinogenic alkylating substances IV. 1,3-Propane sultone and 1,4-Butane sultone. Z. Krebsforsch. 75: 69-84.

Ehrenberg, E., Lundquvist, U., Osterman, S. and Sparrman, B. 1966: On the mutagenic action of alkane sulfonate esters in barley. Hereditas 56: 277-305.

- and Gichner, T. 1967. On the mutagenic action of n-alkyl-n-nitrosamides in barley. Biol. Zentralblatt. 86: 107-117.

Gichner, T. and Veleminsky, J. 1967. The mutagenic activity of 1-alkyl-1-nitrosoureas and aalkyl-3-nitro-1-nitrosoguanidines. Mutation Res, 4: 207-212.

- and - 1973. Toxic and genetic factors limiting the increase of mutation frequency after treatment by alkylating nitroso compounds and X-rays on Arabidopsis seeds. Biol. Plant (Pratia) 15 (5): 350-353.

Gustafsson, A. 1940. The mutagenic spectrum of the chlorophyll apparatus. Acta Univ. Lund. 236: $1-10$.

Hasegawa, H. and Inoue, M. 1980. Mutagenic effect of sodium azide in barley. Japan. J. Breed. 30(1): 19-26.

Kalia, C. S. and Singh, M. P. 1973. The effect of NMU, NMG on chromosome structure and mitotic activity under different $\mathrm{pH}$ and temperature conditions in Allium cepa. Caryologia 26: $337-355$

Kamra, O. P. and Brunner, H. 1970. Chemical mutagens. Mode of action, methods of treatment. 
In, Manual on Mutation Breeding. IAEA, Vienna: 62-64.

Kapoor, C. 1967. Chemical mutagenesis in sorghum. Ind. J. Genet. Pt. Breed. 27 (3): 499-507.

Kaul, B. L. and Singh, C. 1971. Propane sultone mutagenesis in higher plants I. Dose response studies. Z. Pflanzenzücht. 65: 76-83.

- and Zutshi, U. 1972. On the cytogenetic activity of Butane sultone, a new mutagen. Sci. Cult. 38: 284-285.

Konzak, C. F., Nilan, R. A., Harle, J. R. and Heiner, R. E. 1961. Control of factors affecting response of plants to mutagens. Brook Haven. Symp. Biol. 14: 128-154

-, - , - and -. 1964. Efficient chemical mutagenesis In: Manual on Mutation Breeding. Pergamon Press. 49-70.

-, Wickham, I. M. and Dekock, M. J. 1972. Advances in methods of mutagen treatment. In: Induced Mutations and Plant Improvement. IAEA, Vienna: 95-119.

Mehra, P. N. and Mann, S. K. 1974. Cytological effects of chemical mutagens on Pterotheca falconeri. I. Monofunctional alkylating agents. The Nucleus 17 (3): 167-182.

Mohan Rao 1972. The influence of $\mathrm{pH}$ on damage induced by diethyl sulphate in barley. Mutation Res. 15: 155-167.

Muller, A. J. 1966. Die Induktion von rezessiven letalen Mutationen durch Altiylmethansulfinat bei Arabiodopsis I. Dose-effekt Beziehugen. Züchter 36: 201-202.

- and Gicher, T. 1963. Mutagenic activity of 1-methyl-3-nitro-1-nitrosoguanidine on Arabidopsis Arabidopsis. Nature 21: 1149.

Narayanan, K. 1970. Factors influencing the biological effect of alkylating agents. Ph. D Thesis Washington State University.

Osterman Golkar, S and Wachtmeister, C. A. 1976. On the reaction kinetics in water of 1,3Propane sultone and 1,4-Butane sultone. A comparison of reaction rates and mutagenic activities of some alkylating agents. Chem. Biol. Interact. 14: 195-202.

Prina A. R. and Favret, E. A. 1983. Parabolic effect in sodium azide mutagenesis in barley. Hereditas 98: 98-84.

Ramanna, M. S. and Natarajan, A. T. 1965. Studies on the relative mutagenic efficiency of alkylating agents under different conditions of treatment. Indian J. Genet. 25: 24-25

Sarma, N. P., Patnaik, A and Jachuck, J. 1979. Azide mutagenesis in rice. Effect of concentration and soaking time on induced chlorophyl mutation frequency. Indian J. Expt. Biol. 19: 117-121.

Singh, C. and Kaul, B. L. 1973. Propane sultone mutagenesis in higher plants II. Influence of some pre and post treatment conditions. Indian J. Agri. Res. 7: 147-152.

- and - 1978a. Role of pH in chemical mutagenesis. J. Sci. and Ind. Res. 37: 426-432.

- and - 1978b. Propane sultone, a powerful mutagen for barley. Mutation Res. 56: 355-357.

- 1979. Biological effects of Propane sultone in barley. Z. Pflanzeunszucht. 82 : 278-281.

-, Olejniczak, J., Hoppe, P. and Patyna, H. 1980. Effect of growth regulators on sodium azide induced genetic damage in barley. Biol. Plant 22 (2): 91-96.

Veleminsky, J. and Gichner, T. 1970. The influence of $\mathrm{pH}$ on the mutagenic effectiveness of nitroso compounds in Arabidopsis. Mutation Res. 10: 43-52.

Ulland, B. M., Finkelstein, M., Weisburger, K. M., Elizabeth, K. Rice, J. M., Weisberger, F and John. H. 1971. Carcinogenicity of industrial chemicals, propyleneimine and Propane sultone. Nature (London) 230: 460-461.

Zutshi, U. and Kaul, B. L. 1975. Polyploidy and sensitivity to alkylating mutagens. Radiat. Bot. 15: $59-68$. 